\title{
Modeling and Simulation of Buck-Boost Converter with Voltage Feedback Control
}

\author{
Xuelian Zhou ${ }^{1}$, Qiang He ${ }^{1, a}$ \\ ${ }^{1}$ College of Computer and Information Science, Southwest University in No.2, Tiansheng Street,Beibei,Chongqing, China
}

\begin{abstract}
In order to design the control system, it is necessary to have an exact model of buck-boost converter. This paper put forward the transfer function model of buck-boost converter by the state-space average method. The openloop transfer function model of uncompensated system is deduced according to the mathematic model of the buckboost converter, the controller is designed according to frequency domain. The phase and magnitude margin of the open-loop system of the buck-boost converter with compensator have both been increased. After compensating, this control system has the advantages of small overshoot and short settling time. It can also improve control system's real time property and anti-interference ability.
\end{abstract}

\section{Introduction}

With the development of power electronics, switching power supplies are widely used in various occasions, such as cars, ships, aircraft and computers [1]. In many applications such as electronic devices in cars, portable devices, etc, where the output voltage range of the battery is considerably large, buck-boost converters are required. Buck-Boost converter with simple structure, easy to implement, etc, has been widely used in various occasions.

Buck-Boost converter is a basic topology of DC-DC switching converter. There are numerous types of buckboost converters such as the SEPIC converter [2], the non-isolated Cuk converter, the Zeta converter [3] and the Sheppard-Taylor topologies [4].A buck-boost converter provides an output voltage that may be less than or greater than the input voltage. In order to achieve a proper design and control, it is necessary to have an exact model of converter. By modelling the dc-dc converters, the operation of converter in different operational modes can be investigated in both transient and steady states. High accuracy and low response time are major features of the good modelling. The voltage mode controller is designed to improve the control performance of buck-boost converter

\section{System model building}

The power stage of a buck-boot converter is shown as Fig.1. It is composed of the diode VD, the switch transistor $\mathrm{Q}$, the output smoothing capacitance $C$, the output smoothing inductance $L$ and the actual load $R$.

\footnotetext{
a Corresponding author: heq@swu.edu.cn
}

\subsection{Principle of Buck-Boost converter}

The circuit of Buck-Boost converter operation can be divided into two distinctive modes: discontinuous conduction mode (DCM) and continuous conduction mode (CCM). The critical value of the inductor $L_{\mathrm{C}}$ can be expressed as Eq.1. If the value of the inductor $L$ is less than the critical value $L_{\mathrm{C}}$, the buck-boost converter works in discontinuous conduction mode (DCM). Otherwise, it works in continuous conduction mode (CCM).

$$
L_{C}=(1-\alpha)^{2} R T
$$

Where $T$ is the switch cycles.

The output voltage is determined by Eq.2.According Eq.2, it allows the output voltage to be lower or higher than the input voltage, which is determined by the duty ratio. When $\alpha$ less than 0.5 , output voltages will less than input voltage. Otherwise, output voltages will higher than input voltage.

$$
V_{o}=\frac{\alpha}{1-\alpha} V_{g}
$$

Where $V_{\mathrm{g}}$ is the input voltage and $\alpha$ is the duty ratio. The ripple voltage can be expressed as Eq.3

$$
\frac{\Delta V_{o}}{V_{o}}=\frac{\alpha T}{C R}
$$

When buck-boost converter operates in CCM, it can be divided into two modes in every switching period [5]. During mode1 1 , the diode VD is reversed biased and transistor $\mathrm{Q}$ is turn on. The input current flows into 


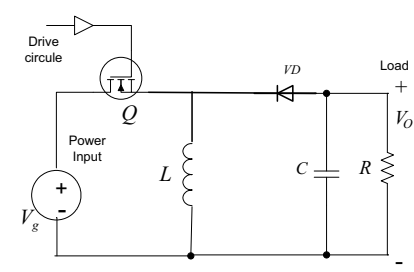

Figure 1. The topology for buck-boost converter

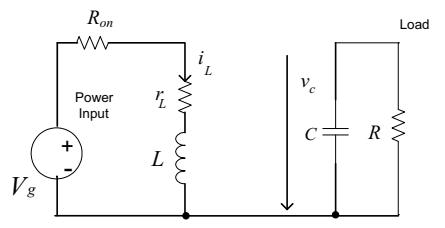

Figure 2. The equivalent circuit for mode 1

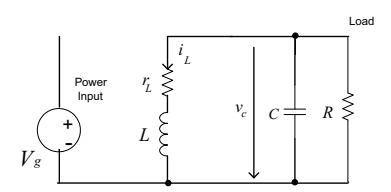

Figure 3. The equivalent circuit for mode 2

inductor $L$ and transistor $\mathrm{Q}$. The inductor current will raise and the Inductor $L$ will store energy. At the same time, capacitance $C$ supplies the load $R$. Its equivalent circuit is shown as Fig.2. AS shown in Fig.2, $i_{\mathrm{L}}$ and $v_{\mathrm{c}}$ are the inductor current and the capacitor voltage respectively. $R_{\text {on }}$ is on-resistance of transistor Q. $r_{\mathrm{L}}$ is on-resistance of the Inductor $L$.

During mode 2, transistor $Q$ is turns off and the current, which was flowing through inductor L, will flow through $L, C, \mathrm{VD}$ and the load $R$. At the same time, the inductor current will fall until the transistor Q is switched on. Its equivalent circuit is shown as Fig. 3

\subsection{Building model of transfers function for Buck-Boost converter}

The theory of state-space averaging applied in the switch-mode power converter was conceived in the early 1970s and well developed in the early 1980s [6]. Dr. Robert Middlebrook and his graduate student Dr. Slobodan Cuk were credited with the concept and techniques associated with it. Therefore, the switch-mode converter models generated on the basis of the theory have oftentimes been named Middlebrook models [7].

Mode 1. While the switch Q is in open position, the equivalent was shown as Fig. 2. Applying Kirchoff's voltage law $(\mathrm{KVL})$, the inductor current, capacitor voltage are described as Eq.4.

$$
\left\{\begin{array}{l}
\frac{d i_{L}}{d t}=-i_{L} \frac{\left(R_{o n}+r_{L}\right)}{L}+\frac{V_{g}}{L} \\
\frac{d v_{c}}{d t}=-\frac{v_{c}}{R C}
\end{array}\right.
$$

The linear circuit is described by means of the statevariable vector $\mathrm{x}$ consisting of the inductor current and

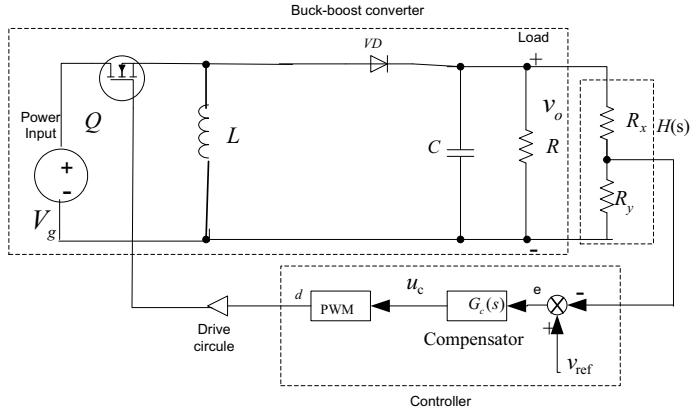

Figure 4. The diagram of closed-loop system of buck-boost converter

the capacitor voltage. When written in state-space form, these equations become as Eq.5.

$$
\begin{aligned}
& \dot{x}=A_{1} x+B_{1} V_{g} \\
& y=C_{1} x \\
& \left(A_{1}=\left[\begin{array}{cc}
-\frac{R_{o n}+r_{L}}{L} & 0 \\
0 & -\frac{1}{R C}
\end{array}\right], B_{1}=\left[\begin{array}{c}
\frac{1}{L} \\
0
\end{array}\right], x=\left[\begin{array}{c}
i_{L} \\
v_{c}
\end{array}\right]\right. \\
& \left.C_{1}=\left[\begin{array}{ll}
0 & 1
\end{array}\right], y=V_{O}=v_{c}\right)
\end{aligned}
$$

Mode 2. While the switch $\mathrm{Q}$ is in close position, in a similar manner, these equations become as Eq.6.

$$
\begin{aligned}
& \dot{x}=A_{2} x+B_{2} V_{g} \\
& y=C_{2} x \\
& \left(A_{2}=\left[\begin{array}{cc}
-\frac{r_{L}}{R C} & \frac{1}{L} \\
-\frac{1}{C} & -\frac{1}{R C}
\end{array}\right], B_{2}=\left[\begin{array}{l}
0 \\
\frac{1}{L}
\end{array}\right], x=\left[\begin{array}{l}
i_{L} \\
v_{c}
\end{array}\right]\right. \\
& \left.C_{2}=\left[\begin{array}{ll}
0 & 1
\end{array}\right], y=V_{O}=v_{c}\right)
\end{aligned}
$$

The averaged matrix $A$ is as Eq.7.

$$
\begin{aligned}
A & =\alpha A_{1}+(1-\alpha) A_{2} \\
& =\left[\begin{array}{cc}
-\frac{\alpha\left(R_{o n}+r_{L}\right)}{L}-\frac{(1-\alpha) r_{L}}{R C} & \frac{(1-\alpha)}{L} \\
-\frac{(1-\alpha)}{C} & -\frac{1}{R C}
\end{array}\right]
\end{aligned}
$$

In a similar manner, the averaged matrices $\mathrm{B}$ and $\mathrm{C}$ are evaluated, with the following results:

$$
\begin{aligned}
& B=\alpha B_{1}+(1-\alpha) B_{2}=\alpha B_{1} \\
& C=\alpha C_{1}+(1-\alpha) C_{2}=C_{1}=C_{2}
\end{aligned}
$$

The steady-state is shown as Eq.9.

$$
X=-A^{-1} B V_{g}=\left[\begin{array}{c}
\frac{\alpha V_{g}}{(1-\alpha)^{2} R+\alpha\left(R_{o n}+r_{L}\right)+\frac{(1-\alpha) r_{L} L}{R C}} \\
-\frac{\alpha(1-\alpha) V_{g}}{\frac{\alpha\left(R_{o n}+r_{L}\right)}{R}+\frac{(1-\alpha) r_{L} L}{R^{2} C}+(1-\alpha)^{2}}
\end{array}\right]
$$


The transfer function from the control input (duty ratio $\alpha$ ) to output (the capacitor voltage $v_{\mathrm{c}}$ ) expresses as Eq.10.

$$
\begin{aligned}
G_{v d}(s)= & C(s I-A)^{-1} B\left[\left(A_{1}-A_{2}\right) X\right. \\
& \left.+\left(B_{1}-B_{2}\right) V_{g}\right]+\left(C_{1}-C_{2}\right) X
\end{aligned}
$$

Because $R_{\text {on }}$ and $r_{\mathrm{L}}$ is very small, they can be ignored. $G_{v d}(\mathrm{~s})$ was simplified as Eq.11.

$$
G_{v d}(s)=\frac{V_{g}\left[\frac{\alpha L}{R} s-(1-\alpha)^{2}\right]}{(1-\alpha)^{2}\left[L C s^{2}+\frac{L}{R} s+(1-\alpha)^{2}\right]}
$$

The transfer function from input voltage $V_{\mathrm{g}}$ to output $v_{\mathrm{c}}$ was shown as Eq.12

$$
G_{v g}(s)=\frac{\alpha(\alpha-1)}{L C s^{2}+\frac{L}{R} s+(1-\alpha)^{2}}
$$

The transfer function of the pulse-width modulator is described as Eq.13

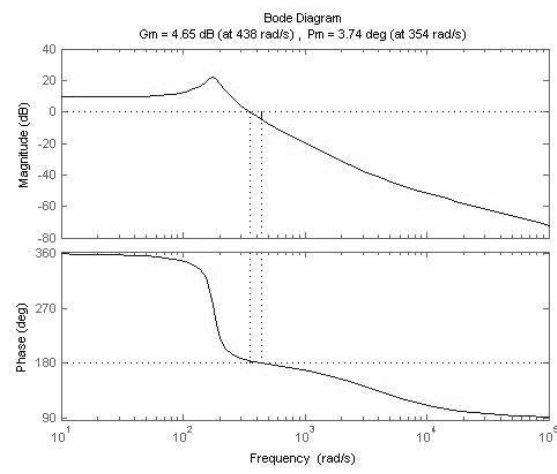

Figure 5. Bode plot of buck-boost converter without compensator

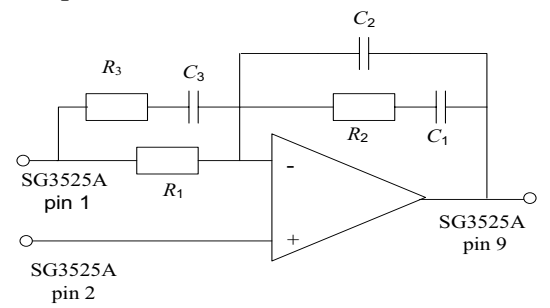

Figure 6. Compensator

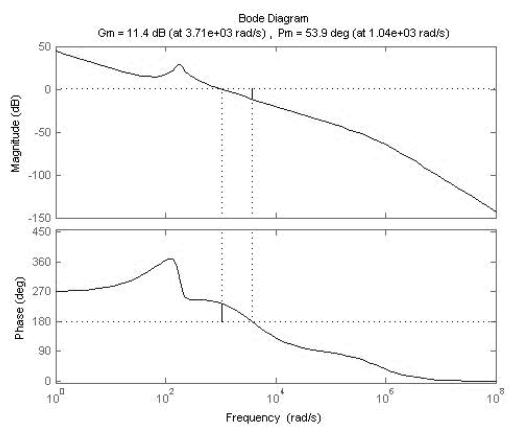

Figure 7. Bode plot of buck-boost converter with compensator

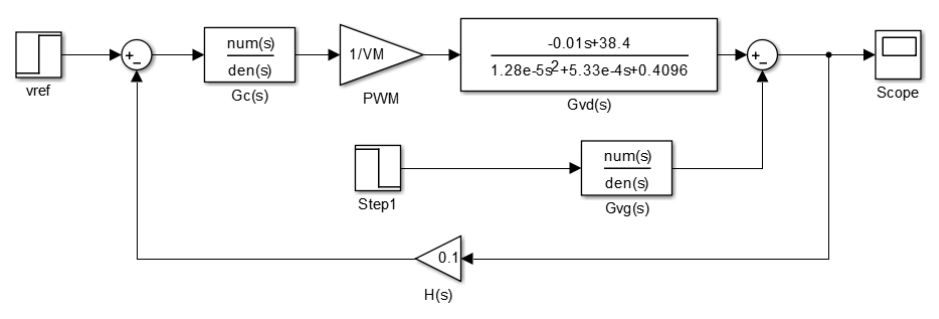

Figure 8. Simulation diagram of buck-boost converter

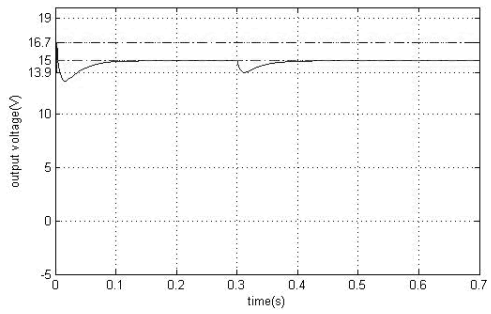

Figure 9. Simulation results of buck-boost converter with voltage disturbance

$$
G_{d c}(s)=\frac{1}{V_{m}}
$$

$V_{\mathrm{m}}$ is the maximum of the saw tooth wave of the pulse-width modulator. For pulse-width modulator $\mathrm{SG} 3525 \mathrm{~A}, V_{\mathrm{m}}$ is 3.2 [8].

\section{Design of control system}

The specifications of buck-boost converter switching power supply design are as follows:

- Switch cycles $T$ is $250 \mu \mathrm{s}$.

- Input voltage is between $20 \mathrm{~V}$ and $64 \mathrm{~V}$.

- Maximum output ripple is no greater than $0.04 \mathrm{~V}$. Output voltage is $16 \pm 0.02 \mathrm{~V}$.

As shown Fig.4, Independent of various operating conditions, such as the output loading, input voltage, and the ambient temperature, the value of voltage of buckboost converter must remain constant. To perform such a task, a portion of the circuit must be insensitive to any of the above variations. This portion is called the reference, usually a voltage source, $V_{\text {ref }}$, which is precise and well stable over temperature.

The load resistor is varied from $10 \mathrm{ohm}$ to $100 \mathrm{ohm}$. The critical inductor was described as Eq.1. According to Eq.1, the value of inductor $L_{\mathrm{c}}$ is $1 \mathrm{mH}$. Considering the margin of continuous conduction mode, the value of inductance $\mathrm{L}$ is $5 \mathrm{mH}$

According to Eq.2, the duty ratio $\alpha$ is 0.2 .

According to Eq.3, the value of capacitance $\mathrm{C}$ is $200 \mu$ F.Considering the margin of capacitor, the value of capacitor $\mathrm{C}$ is $600 \mu \mathrm{F}$.The value of $R_{\mathrm{x}}$ is $90 \mathrm{k} \mathrm{ohm}$. The value of $R_{\mathrm{y}}$ is $10 \mathrm{k} \mathrm{ohm}$. According to Eq.14, $\mathrm{H}(\mathrm{s})$ is 0.1 .

$$
\begin{gathered}
H(s)=R_{y} /\left(R_{x}+R_{y}\right)=0.1 \\
G_{o}(s)=G_{v d}(s) G_{d c}(s) H(s)=\frac{1.2-3.1 \times 10^{-4} s}{1.28 \times 10^{-5} s^{2}+5.33 \times 10^{-4} s+0.4096}
\end{gathered}
$$


AS shown in Eq.15, the uncompensated system has a zero and two close poles. The zero is described as Eq.16. It has a right half-plane zero (RHP), which is also called non-minimum phase system (NMP). The two close poles is described as Eq.17.

$$
\begin{gathered}
\omega_{z z 1}=\frac{(1-\alpha)^{2} R}{\alpha L}=3840 \\
\omega_{p p 1}=\omega_{p p 2} \approx \frac{1}{\sqrt{L C}}=223.6
\end{gathered}
$$

The open-loop transfer function of the uncompensated system was shown as Eq.15. Its bode plot is shown as Fig.5. As shown as Fig.5, the phase margin of the openloop system only reaches to $3.74^{\circ}$. The magnitude margin of the open-loop system is above $4.65 \mathrm{db}$. Both of them are too smaller. The phase margin of control system must be greater than $30^{\circ}$. The magnitude margin of control system must be greater than $6 \mathrm{db}$.So, one must design a compensator to improve the magnitude margin and phase margin of the buck-boost converter.

SG3525A was selected as controller. The SG3525A, pulse width modulator control circuits, can offer lower external parts count and improved performance when implemented for controlling all types of switching power supplies [9]. Compensation network is designed between pin 9 and pin 1. That is shown as Figure 6. The transfer function of compensator is described as Eq.18. It provides two zeros and three poles with one pole located at the origin shown as Eq.19 and Eq.20. The pole at the origin is used to improve the DC regulation. The other pole is used to compensate for the right half-plane zero.

$$
\begin{gathered}
G_{c}(s)=\frac{\left(1+s R_{2} C_{1}\right)\left[1+s\left(R_{1}+R_{3}\right) C_{3}\right]}{\left[s R_{1}\left(C_{1}+C_{2}\right)\right]\left(1+s \frac{R_{2} C_{1} C_{2}}{C_{1}+C_{2}}\right)\left(1+s R_{3} C_{3}\right)} \\
\omega_{z 1}=1 /\left(R_{2} C_{1}\right), \omega_{z 2}=1 /\left(R_{1} C_{3}\right) \\
\omega_{p 1}=0, \omega_{p 2}=1 /\left(R_{3} C_{3}\right), \omega_{p 3} \approx 1 /\left(R_{2} C_{2}\right)
\end{gathered}
$$

The two zeros of compensator are designed to $\omega_{p p 1} / 3$ shown as Eq.21. The pole $\omega_{p 2}$ of compensator is designed to compensate the zero of the uncompensated system shown as Eq.22. The pole $\omega_{p 3}$ is described as Eq.23.The value of the crossover frequency of the feedback system is designed to 1047.

$$
\begin{gathered}
\omega_{z 1}=\omega_{z 2}=\omega_{p p 1} / 3=223.6 / 3 \approx 74.6 \\
\omega_{p 2}=\omega_{z z 1}=3840 \\
\omega_{p 3}=\frac{2 \pi \times 3}{T}=9.4 \times 10^{5}
\end{gathered}
$$

The gain $A_{V 2}$ is shown as Eq.24.

$$
A_{V 2}=\frac{\omega_{p 2}}{\omega_{c}\left|G_{0}\left(j \omega_{c}\right)\right|}=\frac{3840}{1047 \times 0.0912} \approx 40.2
$$

The value of $R_{2}$ is $5000 \mathrm{Ohm}$. The value of $R_{3}$ depends on Eq.25. The value of $C_{1}$ is determined by Eq.26. The value of $C_{2}$ depends on Eq.27. The value of $C_{3}$ is determined by Eq.28. The value of $R_{2}$ depends on Eq.29

$$
\begin{gathered}
R_{3}=\frac{R_{2}}{A V_{2}} \approx 124 \Omega \\
C_{1}=1 /\left(\omega_{z 1} R_{2}\right) \approx 2.68 \mu F \\
C_{2}=\frac{1}{\omega_{p 3} R_{2}} \approx 0.21 n F \\
C_{3}=1 /\left(\omega_{p 2} R_{3}\right) \approx 2.1 \mu F \\
R_{1}=1 /\left(\omega_{z 2} C_{3}\right) \approx 6.4 k \Omega
\end{gathered}
$$

As shown in Fig.7, the phase margin of the open-loop system with compensator reaches to $53.9^{\circ}$. The magnitude margin of the open-loop system of the buckboost converter with compensator is $11.4 \mathrm{db}$.So the control system with compensator is stable

\section{Simulation experiment}

In Fig.8, the simulation model of buck-boost converter is shown based state-space averaging method. In Fig.9, the simulation results were presented. Obviously, the output voltage follows the set-value very well.

As shown as Fig.9, overshoot of the control system was no more than $11.3 \%$. The settling time of it is less than 0.1 second. The ripple of the output voltage is no more than $0.01 \mathrm{~V}$ in stead state. In Fig.9, the simulation model of buck-boost converter with voltage disturbance based state-space averaging method was shown. At the time 0.3 second, a voltage disturbance imposed on the control system changed by $30 \mathrm{~V}$. The voltage drop is no more than $1.1 \mathrm{~V}$. The disturbance recovery time is no more than 0.1 second. According to simulation results, it can resist the supply disturbance very well. These models are simulated by using Matlab R2012b.

\section{Conclusions}

Buck-boost converter is a time-variant and nonlinear dynamic system. Under the assumption conditions of low-frequency small ripple wave and small signal, the mathematic model of buck-boot converter are built up with state-space averag-ing method. One has offered an extremely simple design solution to the problem of output-feedback regulation for buck-boost converter which is insensitive to un-certainty in the voltage disturbance. The experimental results show that the control system has the advantages of small overshoot and short settling time, which better meet the requirements of complicated operation condition of buck-boost con-verter. 
It can also improve control system's real time property and anti-interference ability.

\section{Acknowledgements}

This work was supported in part by the Research Programs for the standardiza-tion administration of the People's Republic of China under Grant No. 20150009-T604. This work was also supported in part by Chongqing Engineering Research Center for Instrument and Control Equipment.

\section{References}

1. V. Samavatian and A. Radan, Electrical Power and Energy Systems. 63,6(2014)

2. J.N. Lou,X.B. Wu,M.L. Zhao et al, Microelectronics Journal. J. E 42,5((2011)

3. S. Singh, B. Singh, G. Bhuvaneswari et al, 2014 IEEE International Conference on Power Electronics, Drives and Energy Systems. 25 (2014)

4. H. M. Mahery and E. Babaei, Electrical Power and Energy Systems. 44,8 (2013)

5. C. T. Rim, G. B. Joung, and G. H. Cho, IEEE Transactions on power electronics. 25,4 (2009)

6. Y.h. Hu and W.P. Cao ,Renewable Energy. 75,8 (2015)

7. N. A. Ahmed, Electric Power Systems Research. 73,4 (2013)

8. Q. He, Applied Mechanics and Materials. 669 (2014).

9. M. H. Rashid, Power Electronics: Circuits, Devices and Applications (2013) 